EREM 75/2

Journal of Environmental Research, Engineering and Management Vol. 75 / No. 2 / 2019

pp. 7-14

DOI 10.5755/j01.erem.75.2.22995
Food Waste Generation: Restaurant Data and Consumer Attitudes

Received 2019/03

Accepted after revision 2019/03

\title{
Food Waste Generation: Restaurant Data and Consumer Attitudes
}

\section{Renata Dagiliūtė*, Aira Musteikytè}

Vytautas Magnus University, Department of Environmental Science, Vileikos 8, Kaunas LT 44404, Lithuania

*Corresponding author: r.dagiliute@gmf.vdu.lt

Food waste and related negative impacts are gaining attention at all policy levels. Therefore, there is an increased need for research and analysis in the field, especially in different countries and different sectors. In Lithuania, so far there are only a couple of studies regarding food waste as such; thus, the aim of this study is to estimate food waste generation in one of food supply chain stages - catering at the restaurant - and to determine restaurant costumers' attitudes towards food waste and related aspects. Results indicate that there are weekly and daily variations in food waste generation per capita. The biggest share of wasted food was composed of grain/cereal products. Shame was identified as one of the reasons for not taking plate leftovers home. However, restaurants could employ activities like educating its consumers or providing personalised portions. In general, consumers indicated lack of information on food waste problems and related environmental impacts, although at home the majority of respondents throw away food that is still good to consume rather often. Hence, information provision and greater attention both from consumers and service providers could be a significant input to food waste reduction in the public catering service sector.

Keywords: food waste generation, restaurant, attitudes, behaviour.

\section{Introduction}

Approximately one third of households' total environmental impact relates to food and drink consumption (EEA, 2005). Referring to life cycle analysis, the main environmental impacts from the food system include soil degradation, water and energy consumption, eutrophication and water pollution, biodiversity loss, introduction of hazardous chemicals, cultivation of genetically modified organisms, air pollution and waste disposal (Tukker et al., 2011; FAO, 2013).

Nevertheless, around 88 million tonnes of food are annually wasted in the European Union; the global volume of food wastage is estimated at 1.6 billion tonnes 
per year. A study in the United States (US) indicates 70 million tonnes of edible food loss (Dou et al., 2016). According to FAO (2013), 31-39\% of food is wasted at the consumption level in developed regions. This wastage not only has an enormous negative impact on the global economy and food availability, but it also causes major environmental impacts and has social implications. As summarised by Thyberg and Tonjes (2016), economic cost depending on different sectors included could amount to 18.3 billion dollars a year in the United Kingdom and to 750 billion dollars globally. In addition, as a study (Ventour, 2008) on British households indicates, $61 \%$ of wasted food could be consumed if it were better handled. Also, some food waste could be used for animal feeding and industrial users depending on the supply chain stage (Dou et al., 2016). These aspects are of special importance in the light of growing population, demand and inequality issues (Godfray et al., 2010).

To address food waste and related impacts, Roadmap to a Resource Efficient Europe (COM (2011) 571) aims to change consumption patterns and achieve a $20 \%$ reduction in the food chain's resource inputs as well as halve the disposal of edible food waste in the EU by 2020 . The EU action plan for the Circular Economy $\mathrm{COM} / 2015 / 0614$ final aims to reduce by half food waste in EU by 2030. New directive 2018/851 amending waste directive aims at global food waste reduction per capita by 50\% until 2030 and also urges Member States to establish specific food waste prevention measures, including awareness campaigns. Hence, changes in consumption patterns are of importance to reach food waste reduction aims and reduce related impacts.

Usually, the whole food supply chain (Dou et al., 2016) is addressed regarding food waste generation. However, different parts of the supply chain contribute differently to food waste in different regions. It is estimated that processing, distribution and consumption in middle and high-income regions accounts for $31-39 \%$ of food wastage but much lower in low-income regions, i.e., 4-16\% (FAO, 2013). Hence, catering services and final consumers are responsible for a significant part of food waste generated in developed countries. Some of the supply chain parts are addressed especially seldom, for example, the retail sector (Cicatiello et al.,
2016; Kliaugaite \& Kruopienè, 2017) or food/catering service (Whitehair et al., 2013; Betz et al., 2015). It is estimated that on average $27 \mathrm{~kg}$ per capita of food waste is generated in the food service/catering sector in old EU members and about $12 \mathrm{~kg}$ per capita in new EU member states (EC, 2011). In total, this amounts to around 12.3 million tonnes of food waste or $13.8 \%$ of all food waste in EU27 annually (EC, 2011). Solely the restaurant sector in the US is responsible for 41 million tonnes of waste generated (Dou et al., 2016). Denmark workplace canteens generate 33 thousand tonnes of food waste per year (Halloran et al., 2014). Finnish food service sector is estimated to generate 75-85 million $\mathrm{kg}$ per year of food waste, some 7-28\% being cooked meal (Katajajuuri et al., 2014). Majors types of food wasted in canteens and restaurants include meat, cereals and vegetables (Halloran et al., 2014). As eating out is increasing in the developed world, there is an assumption that there will be significant shifts of food quantities and types in-between households and food services (Thyberg \& Tonjes, 2016). The main reasons for waste generation in food service industry include oversized dishes, buffet offers for a fixed price, use of single portion packs for jams, juice, milk, underestimation of demand (Priefer et al., 2016), ordering too much (Papargyropoulu et al., 2016), lack of hunger, disliked ingredients, disliked dish, etc. (Betz et al., 2015).

Analysis of different factors determining food waste-related attitudes and behaviour usually include a number of sociodemographic aspects like gender, age, income, family size and education. There are studies suggesting that younger people tend to waste more (Stefan et al., 2013; Secondi et al. 2015). Also, larger households (Koivupuro et al., 2012) and households with higher incomes (Stancu et al., 2016) generate more food waste in total. Although there is no uniform agreement regarding gender influence, some studies suggest that single woman households generate more waste per capita than other households (Koivupuro et al., 2012). Betz et al. (2015) also found that women generate more plate waste than men in the food service industry.

Central and eastern Europe Countries like Lithuania lack studies on food waste in the hospitality sector 
and in general. There is a study on the retail sector, comparing different retail chains (Kliaugaite \& Kruopiené, 2017) and unpublished studies regarding food generation in households (KTU, unpublished results). Therefore, this paper could be a starting point for a more detailed analysis of food waste generation in the hospitality sector in Lithuania and could contribute to the data on the topic and policy making as well as to awareness-raising activities.

The aim of the study is twofold. First, the study analyses the amount of food waste generated and being sorted out in a chosen restaurant X (Vilnius, Lithuania); second, it explores consumers' attitude towards food waste generation in general and at public catering places.

\section{Methods}

Catering business $X$ (Vilnius, Lithuania) was closely monitored in terms of customer flows and food waste generated for six months, December through May, one week each day every month of the analysis. Daily observations then were applied for the month totals. Consumers' leftovers and food preparation waste were considered as food waste, although different approaches and definitions could be used, as discussed by various authors (Cicatiello et al., 2016; Dou et al., 2016; Thyberg \& Tonjes, 2016). All generated food waste was weighed. Only total wasted food was monitored in our case.

In order to find out the consumers' opinion about food waste, guests of restaurant $X$ were surveyed. Based on literature review, a questionnaire was prepared by the authors. The questionnaire included general questions about food waste, food waste generation at home, frequency and reasons of discarding food, as well as the most often discarded food products. Another part of the questionnaire was related to eating out, plate wastes, taking away leftovers from the public catering and reasons behind for not doing so. To reveal possible influence of socio-demographic factors, variables like gender, age, education and income were included (Table 1). A total of 174 unique respondents participated in the research in 2016. Mainly, descriptive statistics was applied for the data.

\section{Table 1}

Profile of Respondents $(\mathrm{N}=174)$

\begin{tabular}{l|c|l|c}
\hline $\begin{array}{c}\text { Sociodemographic } \\
\text { Variable }\end{array}$ & $\begin{array}{c}\text { Share of } \\
\text { Respondents }\end{array}$ & $\begin{array}{c}\text { Sociodemographic } \\
\text { Variable }\end{array}$ & $\begin{array}{c}\text { Share of } \\
\text { Respondents }\end{array}$ \\
\hline \multicolumn{1}{c|}{$\begin{array}{c}\text { Gender } \\
\text { Female }\end{array}$} & 2 & 3 & 4 \\
Male & $63.8 \%$ & $\begin{array}{l}\text { Income } \\
<=200 \text { EUR }\end{array}$ & $20.1 \%$ \\
& $36.2 \%$ & $201-350$ EUR & $2.8 \%$ \\
& & $351-500$ EUR & $21.2 \%$ \\
& & $501-650$ EUR & $33.3 \%$ \\
\hline Age & & $651-700$ EUR & $14.9 \%$ \\
mean & & $>=701$ EUR & $7.4 \%$ \\
SD & 34.8 & Education & \\
min & 9.6 & Vocational & $4.6 \%$ \\
max & 18 & Secondary & $20.7 \%$ \\
& 55 & Higher & $74.7 \%$ \\
& & & \\
& & &
\end{tabular}

\section{Results and Discussion}

\section{Consumers' Attitudes and Behaviour Regarding Food Waste in General and at Home}

EU wide surveys indicate that $76 \%$ of Europeans think that the individual consumer is one of the main actors responsible for the prevention of food waste (Flash Eurobarometer 425, 2015). However, in Lithuanian, this percentage is significant lower (44\%).

In our study, the majority of the respondents (91\%) had heard about the problem of food waste generation and management. However, the research reveals a rather low awareness level on food waste-related environmental impacts. More than half of the respondents (66\%) do not know what environmental problems are related to food waste. Only some indicated energy consumption and greenhouse effects as the problems that food waste contributes to (Fig. 1). This suggests that more information and engagement campaigns are needed in the case of Lithuania, as awareness on food waste environmental, social and economic consequences is negatively associated with food waste behaviour (Stancu et al., 2016).

In addition to low environmental consciousness and an inadequate standpoint of consuming too much, the respondents also lacked knowledge of recycling and opportunities to waste less. Some $52 \%$ of 
the respondents throw away not fresh food and food products, which are still suitable for consumption, not considering other options. Some $12 \%$ give food away

\section{Fig. 1}

Knowledge on food waste related environmental problems (survey results)

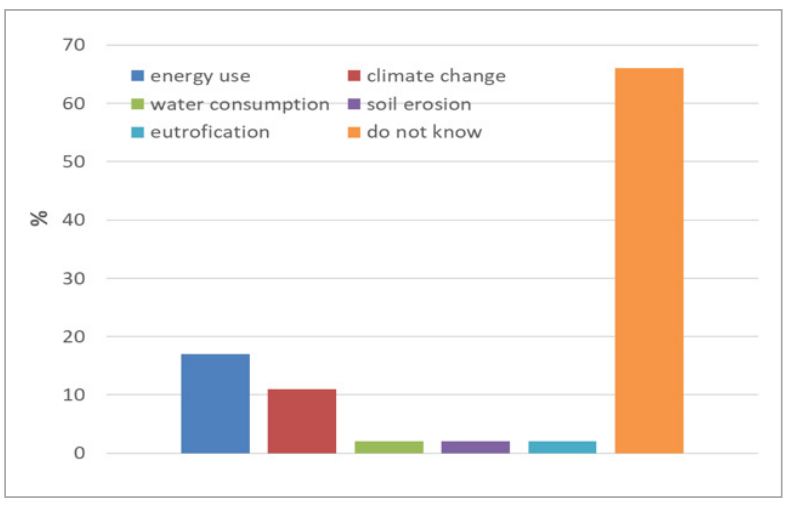

for animal consumption. A rather positive thing is that nearly one-third still try to consume not fresh food which is still good for consumption. In addition, 88\% of the respondents dispose generated food waste together with other municipal waste, and only some $9 \%$ make compost.

According to the respondents, there is a vacuum of information about proper handling of unconsumed food products. The majority of the respondents (71\%) state that there is no such information at all, while $24 \%$ say that there is a lack of information.

Most of the respondents throw away some food up to 2-3 times per week (28\%), $27 \%$ throw food away once per week and $14 \%$ of the respondents do it everyday. The most common cause of food wastage at home is the passed expiry date of food (44\%) followed by freshness (18\%) (Fig. 2). In addition, 59\% of the respondents admitted buying more food than they

Fig. 2

Reasons for wasting food at home (survey results)

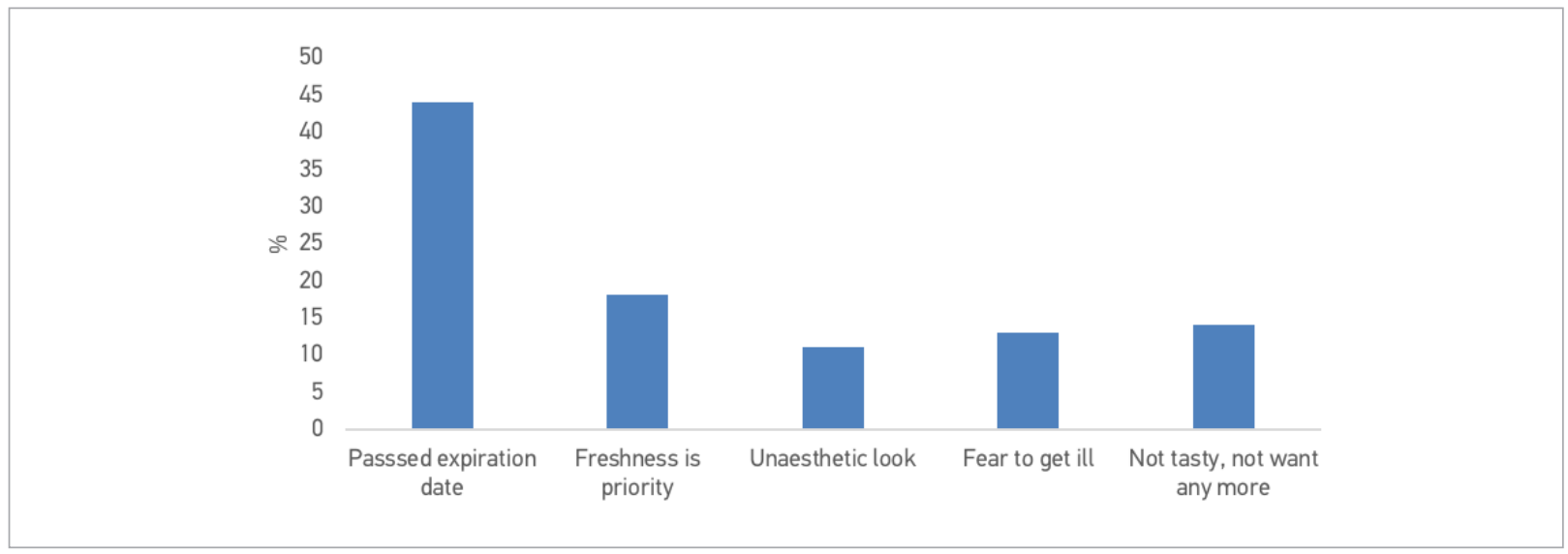

needed. Other studies suggest (Silvennoinen et al., 2014) that the reasons behind food wasted at home is spoiled, mouldy food (29\%), passed expiration date (19\%), plate leftovers (14\%), prepared too much (13\%) and food not wanted anymore (10\%).

\section{Restaurant Food Waste}

The research showed that during the six months 14,744 kilograms of food in total was thrown away in a restaurant. The amount of food waste was linked to the total number of customers during the selected timeframe. Monday was the day with the lowest consumer loads during the whole period under analysis. The highest visitor load was recorded in December $(10,444)$, probably due to the season holiday, and the lowest was in May $(8,084)$ as people tend to be outside more and spend time in the nature. In the spring, the quantities of food wasted decreased due to the seasonality both in total and per capita terms, indicating a lower food demand during the warmer season in general. The weekend effect was also registered (Fig. 3). Observations during restaurant services indicate 
that families with small children tend to leave more uneaten food in their plates.

Compared with other studies, the restaurant data show lower levels of food waste per capita per day. For example, a hotel restaurant in Malaysia indicate $1.1 \mathrm{~kg}$ per capita daily waste generation (Papargyropoulou et al., 2016). This difference might be a result of a different food service approach as hotel service includes breakfast, lunch and dinner. If recalculated per meal, the results would be much more like in our case (0.26 kg/cap on average) (Fig. 3).

\section{Fig. 3}

Weekly variation of food waste generated per capita at the restaurant (research data)

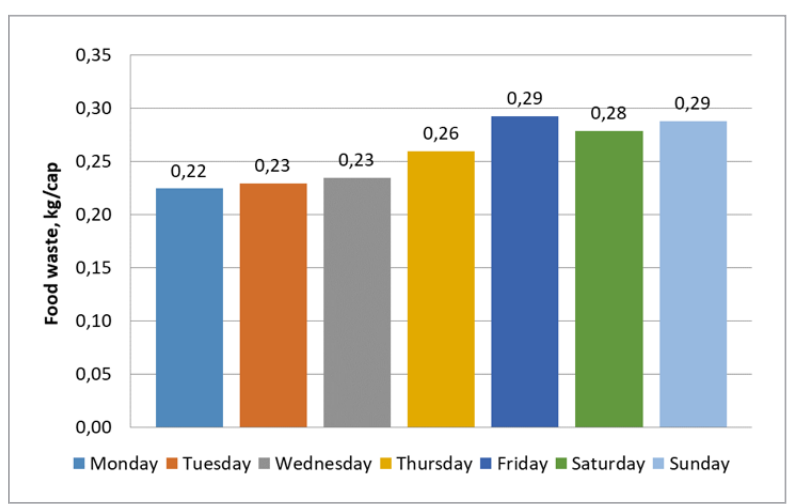

During the study period, grain/cereal products composed the biggest share of all food waste. In total, nearly $6,000 \mathrm{~kg}$ of grain products were discarded composing $40 \%$ of all food waste (Fig. 4). Meat and its products accounted for the smallest share of the restaurant food waste, i.e., $5 \%$ or $744 \mathrm{~kg}$ during the whole period under analysis. Other waste includes other food (e.g., fruits) and prepared meals, which were hard to assign to a certain group. A study of Halloran et al. (2014) indicates that the major types of food wasted in canteens and restaurants are cereals, vegetables and meat, but the latter was not the case in our study. Some similar results were obtained by Betz et al. (2015), indicating that vegetables (27\%) and starch accompaniments (30\%) were dominant in catering companies as food waste. The case of a hotel restaurant also shows that vegetables, cereal and fruits compose the biggest part of food waste generated (Papargyropoulou et al., 2016).
Fig. 4

Food waste structure (research survey)

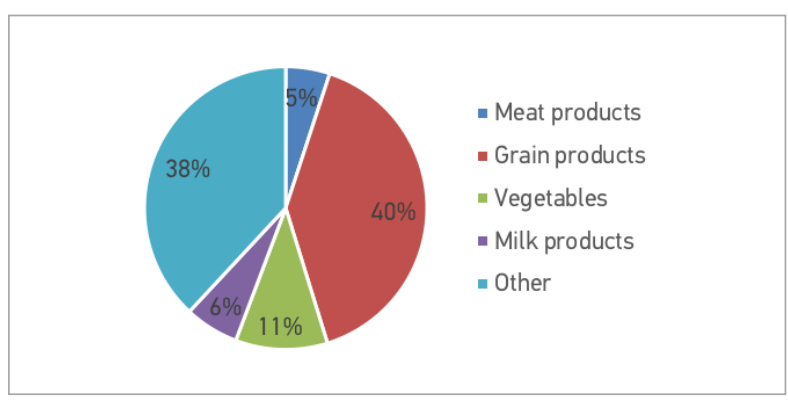

\section{Consumers' Attitudes and Behaviour Regarding Food Waste While Eating Out}

More than half of the respondents state eating out often, and most often in cafes and fast food restaurants. Of those often eating at public caterers, 73\% indicate that they often or always eat all food ordered at a restaurant. Among those who often or always leave some uneaten food, only $5 \%$ always and $22 \%$ often ask to take away left food. Almost half (43\%) of the rest indicate shame as a reason to take food leftovers (Fig. 5). Most often those were with higher education and higher income. It may be argued that people taking away uneaten food associate this with the social status (affordability) and not with the feature of responsible consumption, which no one should be ashamed of.

\section{Fig. 5}

Reasons for avoiding the take away option of leftovers at the restaurant (survey data)

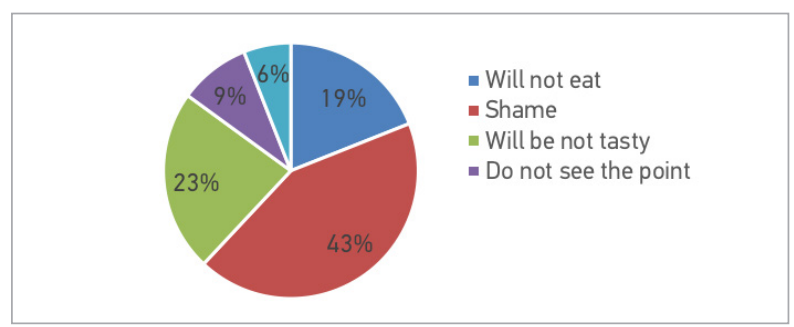

Some $24 \%$ of our respondents' indicate seldom leaving some uneaten food. We did not analyse the reasons for plate waste in our case, but other authors suggest that the dominant reasons for plate waste are too large portions, lack of hunger, not liked 
ingredients, not liked dish, too much of food or too much of seasoning (Betz et al., 2015). Studies suggest that even prompt-type messages like 'eat that you take, don't waste food' might reduce plate waste by $15 \%$ (Whitehair et al., 2013). Together with a reduced plate size, provided messages could lead to food waste reduction by $20 \%$ in a hotel restaurant (Kallbekken \& Sælen, 2013).

\section{Study Limitations}

While considering the study results, it should be taken into account that the study does not differentiate plate and other generated food waste in the restaurant. However, it indicates overall food waste generation. Also, the study covers only half a year and does not provide summer time data, which could be of importance for food waste management and reduction purposes. Seasonal analysis of products wasted could also be beneficial for the restaurant itself for food waste mitigation. Another bias of the research could be a rather small sample of the respondents, which limits statistical analysis and comparability.

\section{Conclusions and Future Implications}

One of the first studies on food waste in Lithuania, and particularly in public catering, indicates that the problem of food waste is relevant in the country. Some public awareness-raising initiatives (e.g., "Sincerely, food" by the Lithuanian Consumer Institute, or social ads on TV) are going on but still might not reach everyone. Although the respondents of the study had no clue on their own negative impact to the environment, they all agree that our society has to have much more information on solving problems like food waste. Therefore, policies to encouraging food saving at home and public places should be promoted to deal with the food waste challenge (Williams et al., 2015). Dou et al. (2016) among other measures for food waste avoidance also indicates the importance of consumer education, as well as mobilisation of stakeholders and innovation fostering for a sustainable food system. In general, awareness raising, engaging and enabling consumers, is one of the ways to achieve desirable behavioural changes for food waste reduction (Dou et al., 2016; Delley \& Brunner, 2017).

Proper legislation is also one of the prerequisites for food waste minimisation, as presented by some authors (Halloran et al., 2014, Thyberg \& Tonjes, 2016). Sometimes, legislation could even increase food waste generated; therefore, comprehensive policies and measures should be addressed. So far, there is no overarching legislation on food waste reduction; only the waste sector follows more or less EU legislation in Lithuania. The National Waste Prevention Programme (2013) aims at implementing the EU waste policy, particularly the EU waste directive and lightweight plastic carrier bags directive. It should be mentioned that biodegradable waste is distinguished as an important waste stream with the focus on food waste as the biggest potential for reduction. For that, the programme foresees public awareness raising on environmental and economic aspects of food waste. Nevertheless, as mentioned before, in most cases, public awareness campaigns on food waste are fragmented. Some training for the public catering sector had to be implemented by the State Food and Veterinary Service in 2014-2015. The Amendment (EU directive 2018/851) to the waste directive and recent European initiatives might be a trigger for new policies and measures implemented. A working group on food waste from different governmental and nongovernmental institutions has already been created to deal with this challenge. Some changes regarding fresh fruit and vegetable standards (excluding safety standards) has come into force since 2019 enabling reduction of food waste in the retail sector and opening better opportunities for food donation and redistribution in general. In addition, it should be taken into account that the food waste rate is still lower in countries like Lithuania; therefore, this should be considered when framing the post-2020 waste prevention programme in Lithuania.

Some authors (Halloran et al., 2014) suggest that more comprehensive research is needed to understand better the food waste generation at different levels of the food supply chain. This could be of special importance as currently very few studies are carried out in Lithuania and countries with similar experiences. Only extrapolated data are used for overall analysis (EC, 2011). 
Nevertheless, the hospitality sector itself could take some actions to reduce food waste generation by offering an individual portion size, more careful menu planning, or educating their customers (Priefer et al., 2016). It is also suggested to improve storage routines and purchasing practices, control food loss during preparation or overproduction (Betz et al., 2015). Providing a possibility to take leftovers could also be an option for food waste reductions, as the study results suggests.

\section{References}

Betz A., Buchli J., Göbel Ch., Müller C. (2015) Food waste in the Swiss food service industry - Magnitude and potential for reduction. Waste Management 35, 218-226. https://doi. org/10.1016/j.wasman.2014.09.015

Cicatiello C., Franco S., Pancino B., Blasi E. (2016) The value of food waste: An exploratory study on retailing. Journal of Retailing and Consumer Services 30, 96-104. https://doi. org/10.1016/j.jretconser.2016.01.004

Delley, M., Brunner, T. (2017) Food waste within Swiss households: A segmentation of the population and suggestions for preventive measures. Resources, Conservations and Recycling 122, 172-184. https://doi.org/10.1016/j.resconrec.2017.02.008

Dou Z., Ferguson J.D., Galligan D.T., Kelly, A. M., Finn S.M., Giegengack R. (2016) Assessing U.S. food wastage and opportunities for reduction. Global Food Security 8, 19-26. https://doi. org/10.1016/j.gfs.2016.02.001

EEA (2005) Household consumption and the environment. European Environment Agency report No 11/2005 (Luxembourg: Office for Official Publications of the European Communities)

European Commission (EC) (2011) Industry, Preparatory Study on Food Waste across EU27. Technical Report - 2010 - 054 [DG ENV - Directorate C], Paris.

FAO (2013) Food wastage footprint. Impacts on natural resources. Summary report. FAO. URL: http://www.fao.org/docrep/018/i3347e/i3347e.pdf

Flash Eurobarometer 425 (2015) Food waste and date marking. Report.

Godfray, H.C.J., Beddington, J.R., Crute, I.R., Haddad, L., Lawrence, D., Muir, J.F., Pretty, J., Robinson, S., Thomas, S.M., Toul$\mathrm{min}, \mathrm{C}$. (2010). Food security: the challenge of feeding 9 billion people. Science 327 (5967), 812-818. https://doi.org/10.1126/ science. 1185383
\{Gurauskiene, 2006, Eco-design methodology for electrical and electronic equipment industry\}

\section{Acknowledgements}

The study was presented at the Fifth International Symposium on Green Chemistry, Sustainable Development and Circular Economy, which took place in Skiathos, Greece, September 30 to October 03, 2018.
Halloran A., Clement J., Kornum N., Bucatariu C., Magid J. (2014). Addressing food waste reduction in Denmark. Food Policy 49, 294-301. https://doi.org/10.1016/j.foodpol.2014.09.005

Kallbekken S., Sælen H. (2013) 'Nudging' hotel guests to reduce food waste as a win-win environmental measure. Economics Letters 119, 325-327. https://doi.org/10.1016/j.econlet.2013.03.019

Katajajuuri J-M., Silvennoinen K., Hartikainen H., Heikkilä L., Reinikainen A. (2014) Food waste in the Finnish food chain. Journal of Cleaner Production 73, 322-329. https://doi. org/10.1016/j.jclepro.2013.12.057

Kliaugaitè D., Kruopienè J. (2017). Food Waste Generation and Prevention Measures in the Retail Sector: A Comparative Study. Journal of Environmental Research, Engineering and Management 74 (1), 7-20

Koivupuro, H.-K., Hartikainen, H., Silvennoinen, K., Katajajuuri, J.-M., Heikintalo, N., Reinikainen, A., et al. (2012) Influence of socio-demographical, behavioural and attitudinal factors on the amount of avoidable food waste generated in Finnish households. International Journal of Consumer Studies 36(2), 183-191 https://doi.org/10.1111/j.1470-6431.2011.01080.x

National waste prevention programme. (2013) Order by Minister of Environment of Republic of Lithuania, No. D1-782, Vilnius Papargyropoulou E., Wright N., Lozano R., Steinberger J., Padfield R., Ujang Z. (2016) Conceptual framework for the study of food waste generation and prevention in the hospitality sector. Waste Management, 49 326-336. https://doi.org/10.1016/j. wasman.2016.01.017

Priefer C., Jörissen J., Bräutigam K.R. (2016) Food waste prevention in Europe-A cause-driven approach to identify the most relevant leverage points for action. Resources, Conservation and Recycling 109, 155-165. https://doi.org/10.1016/j.resconrec.2016.03.004 
Secondi, L., Principato L., Laureti T. (2015) Household food waste behaviour in EU-27 countries: A multilevel analysis. Food Policy 56, 25-40. https://doi.org/10.1016/j.foodpol.2015.07.007

Silvennoinen K., Katajajuuri J-M., Hartikainen H., Heikkilä L., Reinikainen A. (2014) Food waste volume and composition in Finnish households. British Food Journal, 116 (6), 1058-1068. https://doi.org/10.1108/BFJ-12-2012-0311

Stancu V., Haugaard P., Lähteenmäki L. (2016) Determinants of consumer food waste behaviour: Two routes to food waste. Appetite 96, 7-17. https://doi.org/10.1016/j.appet.2015.08.025

Thyberg K. L., Tonjes D. J. (2016) Drivers of food waste and their implications for sustainable policy development. Resources, Conservation and Recycling 106, 110-123. https://doi. org/10.1016/j.resconrec.2015.11.016
Tukker A., Goldbohm R. A., de Koning A., Verheijden M., Kleijn R., Wolf O., Pérez-Domínguez I., Rueda-Cantuche J.M. 2011. Environmental impacts of changes to healthier diets in Europe. Ecological Economics 70, 1776-1788. https://doi.org/10.1016/j. ecolecon.2011.05.001

Ventour, L. (2008) The food we waste. Banbury/Oxon: WRAP. URL: http://wrap.s3.amazonaws.com/the-food-we-waste.pdf

Whitehair, K. J., Shanklin C.W., Brannon L. A. (2013) Written Messages Improve Edible Food Waste Behaviors in a University Dining Facility. Journal of The Academy of Nutrition and Dietetics, 113, 63-69. https://doi.org/10.1016/j.jand.2012.09.015

Williams, I. D., Schneider, F. and Syversen. F. 2015 The "food waste challenge" can be solved. Waste Management, 41, 1-2. https://doi.org/10.1016/j.wasman.2015.03.034 